\title{
Transformações nos objetivos de organizações culturais sem fins lucrativos
}

\author{
Transformation in Objectives of the Non-profit Cultural Organizations
}

Samara Regina Bernardino Hoffmann ${ }^{1}$

Eloise Helena Livramento Dellagnelo ${ }^{2}$

\section{Resumo}

Este artigo apresenta a análise dos objetivos de organizações culturais sem fins lucrativos, vinculadas ao teatro em Florianópolis. Pesquisas anteriores permitiram selecionar para este estudo dois grupos de teatro: Erro Grupo e Dromedário Loquaz. A pesquisa de caráter descritivo e abordagem predominantemente qualitativa buscou descrever com profundidade as informações relativas aos casos pesquisados, de uma perspectiva longitudinal. Percebeu-se, mediante entrevistas semi-estruturadas realizadas com os integrantes dos grupos pesquisados e observação constante das pesquisadoras, que o Erro Grupo evidencia em sua trajetória um desvio de seus propósitos iniciais, enquanto o Dromedário Loquaz apresenta objetivos mais amplos e coerentes com sua atuação ao longo do tempo. A compreensão dos casos mediante a análise de conteúdo e documental sob orientação de duas importantes categorias, grupo teatral (grupos teatrais sem fins lucrativos registrados em Florianópolis) e objetivos organizacionais (analisados a partir da orientação geral, finalidade, atuação, recursos disponíveis e relações externas), convergiu para reflexões sobre a dependência de recursos externos e a influência da perspectiva da economia política na análise dos objetivos das organizações em questão.

Palavras-chave: organizações culturais; objetivos.

\section{Abstract}

This article presents an analysis of the objectives of non-profit cultural organizations linked to the theatre area in Florianópolis. Other researches made possible a selection of two theatre groups for this article: Erro Grupo and Dromedário Loquaz. This descriptive research with a predominant qualitative approach aimed at the profound description of the informations related to the researched cases, based on a longitudinal perspective. The semi-structured interviews made with the members of the organizations as well as observation made by the researchers indicated that Erro Grupo showed itself very far from its initial objectives while Dromedário Loquaz showed broader objectives, which are consistent with its activities throughout time. The comprehension of the cases based on content and documental analysis and orientated by two important categories, theatre group (non-profit groups registered in Florianópolis) and organization's objectives (orientation, purpose, actuation, resources, external relations) resulted in reflections on the dependence on external resources and the influence of political economy perspective on the analysis of these organization's objectives.

Key words: cultural organizations; objectives.

\footnotetext{
${ }^{1}$ Mestre em Administração. Professora da Faculdades Energia de Administração e Negócios - FEAN na Eletrosul Centrais Elétricas S.A. Endereço: ELETROSULCentrais Elétricas S.A. Rua Deputado Antônio Edu Vieira no999 Pantanal- Florianópolis/SC - Brasil - CEP : 88040-901. E-mail: sabernardino@hotmail.com.

${ }^{2}$ Doutora em Engenharia da Produção pela Universidade Federal de Santa Catarina. Professora da Universidade Federal de Santa Catarina. Endereço: Universidade Federal de Santa Catarina - UFSC - Trindade - Florianópolis / Santa Catarina - Brasil - CEP 88040-900. Email: eloise@cse.ufsc.br.

Artigo recebido em julho de 2006 e aceito para publicação em agosto de 2006
} 


\section{0 foco da pesquisa}

Conforme afirmam Goulart, Menezes e Gonçalves (2003), o campo das organizações culturais está sofrendo transformações, especialmente, nas formas de financiamento e gestão, em decorrência das inúmeras mudanças no cenário institucional. De acordo com Leão Jr. (2003) essas mudanças estão relacionadas com a definição do papel social dessas instituições, que por sua vez estão procurando corresponder ao conceito de "um bem requerido pela sociedade". Segundo diferentes autores pesquisados, percebe-se um aumento da competitividade no campo das organizações culturais que converge para o advento de novos arranjos organizacionais, que por sua vez procuram estabelecer padrões de atuação compatíveis com um novo cenário permeado por valores mercantis até então alheios a esse contexto (GAMEIRO; MENEZES; CARVALHO, 2003). Diante dessa conjuntura, afirmam os autores, as organizações tendem a criar novas estruturas e a promover mudanças nos processos de gestão, buscando o aumento da sua capacidade competitiva, assemelhando-se cada vez mais ao comportamento típico de organizações do campo empresarial. Nesse sentido, a busca pela sobrevivência faz com que grande parte das organizações culturais pratique o isomorfismo, ${ }^{1}$ incorporando atitudes de outros grupos, principalmente do setor empresarial (GONÇALVES; MAGALHÃES FILHO; ALCÂNTARA, 2003).

As mudanças no contexto da organização e da coordenação das ações culturais e artísticas podem estar relacionadas à influência de atores até então estranhos a esse universo, reconhecem Goulart, Menezes e Gonçalves (2003). Segundo os autores, a participação de atores internos ou externos ao contexto cultural tem influenciado o comportamento das organizações nesse meio. Percebe-se a crescente incorporação de modelos e práticas de gestão característicos da iniciativa privada. Essas organizações estão alterando a sua lógica de atuação e, muitas vezes, seu propósito de existência (MONTE, 2003). Madeiro e Carvalho (2003) observam em suas pesquisas que, aos poucos, emerge no contexto cultural uma nova estruturação social em que a racionalidade substantiva torna-se meio para a realização de padrões de atuação da racionalidade instrumental.

Com base nessas reflexões, ressalta-se a relevância deste artigo, uma vez que se concentra na análise das transformações nos objetivos de grupos teatrais sem fins lucrativos existentes em Florianópolis (SC), ao longo de suas respectivas trajetórias. Essas organizações, com propósitos teoricamente distintos das empresas lucrativas, incitaram as reflexões e interpretações finais sobre a influência das mudanças no meio em que estão inseridas e a relação de tais mudanças com as transformações percebidas nos seus objetivos. Este artigo preocupou-se em identificar as transformações na natureza dessas organizações, que podem implicar transformações na sua conduta e nos propósitos de sua existência.

A realização deste artigo implicou a definição de uma série de procedimentos metodológicos que devem ser esclarecidos. Inicialmente, um levantamento prévio realizado entre setembro e dezembro de 2004 permitiu identificar 33 grupos teatrais registrados no município de Florianópolis. Desse universo, foram identificados 26 grupos teatrais sem fins lucrativos. Neste estudo são aprofundados dois casos: o Erro Grupo e o Dromedário Loquaz. O primeiro tem uma trajetória de quatro anos e o segundo, com um longo tempo de existência, 25 anos de atuação, é integrante de uma importante associação de classe, a Gesto (Associação de Produtores Teatrais da Grande Florianópolis), um dos atores influentes no ambiente das organizações culturais de Florianópolis.

A pesquisa, de caráter qualitativo, está fundamentada em importantes categorias de análise: grupo teatral, que consiste em grupos sem fins lucrativos registrados em Florianópolis e dedicados a atividades teatrais, e objetivos organizacionais, analisados a partir das dimensões: orientação geral, finalidade, atuação, recursos disponíveis e relações externas. Os dados foram obtidos a partir da realização de entrevistas semi-estruturadas com os integrantes dos respectivos grupos, da observação constante das pesquisadoras em encontros, reuniões, ensaios e apresentações de espetáculos envolvendo os grupos pesquisados, além da análise de documentos disponíveis. A análise comparativa dos casos aqui apresentados foi realizada mediante técnicas de análise de conteúdo e documental, que convergiram em reflexões, evidenciadas ao longo deste artigo, a respeito das transformações nos objetivos das organizações pesquisadas. 


\section{A questão dos objetivos em organizações formais}

As "relações associacionais", diferentemente das "relações comunais" (envolvimento dos indivíduos com atividades resultantes dos laços de amizade, parentesco ou comunidade), requerem a conjugação deliberada de esforços e recursos por indivíduos (não necessariamente ligados por laços afetivos) que buscam alcançar um ou vários objetivos, conforme afirma Marinho (1990). A autora sustenta que a presença de objetivos e a conjugação de esforços por parte dos indivíduos, no sentido de atingir tais propósitos, são elementos característicos das organizações modernas. "A ênfase centrada fundamentalmente no comportamento racional faz das 'relações associacionais' o próprio instrumento para a realização de determinados objetivos e, dessa forma, o conceito de organização complexa.” (MARINHO, 1990, p.6).

Segundo Marinho (1990), os objetivos constituem, portanto, um componente essencial da noção de organização complexa proposta por Etzioni (1967), que concebe as organizações como unidades sociais orientadas à consecução de objetivos ou metas específicas. "[...] o objetivo da organização é a situação futura que a organização, como uma coletividade, procura atingir" (ETZIONI, 1976, p.14). Os objetivos organizacionais são sempre intencionais, a diferença pode estar entre as intenções apresentadas e as reais, enfatiza o autor (ETZIONI, 1976, p.16).

Os objetivos organizacionais incorporam muitas funções. Segundo Etzioni (1976), eles podem indicar a orientação que a organização precisa seguir, conferir legitimidade, justificar de certa forma suas atividades e sua própria existência etc. "As organizações são unidades sociais que procuram atingir seus objetivos específicos, sua razão de ser é servir a esses objetivos." (ETZIONI, 1976, p.13).

Conforme expõe Megginson (1986), os objetivos organizacionais indicam um destino, o resultado final de algo que a organização visa alcançar. Robbins (1981) corrobora afirmando que os objetivos correspondem à finalidade de todas as atividades da organização.

Conforme expõe Perrow (1972), os objetivos da organização são múltiplos, conflitantes e podem ser alcançados simultaneamente ou de forma seqüencial. $\mathrm{O}$ autor distingue cinco tipos de objetivos: os objetivos da sociedade (serve às necessidades da sociedade), os objetivos de produção (elaborados em função do cliente/consumidor), os objetivos de sistemas (voltados ao funcionamento organizacional, à estabilidade, ao lucro e ao crescimento), os objetivos de produtos (voltados às características do produto: qualidade, quantidade e estilo) e os objetivos derivados (uso do poder influenciando os membros e o ambiente). A opção por uma ou por outra categoria de objetivos dependerá daquilo que o pesquisador deseja analisar, afirma Perrow (1972).

Nesse sentido, os objetivos podem ser definidos conforme a lucratividade, o crescimento organizacional, a inserção no mercado, produtividade, consciência social e satisfação do cliente, entre outros aspectos, conforme elenca Robbins (1981). No que concerne às organizações sem fins lucrativos, as mesmas podem classificar seus objetivos conforme as categorias citadas, exceto pela lucratividade, afirma o autor.

Robbins (1981) ressalta a importância de observar a existência dos objetivos declarados e dos objetivos reais; ou seja, muitas vezes as realizações das organizações não correspondem de fato aos seus objetivos declarados (declarações oficiais, normativas e idealistas). Conforme expõe o autor: "Se desejarmos saber quais são os objetivos declarados da organização, devemos procurá-los nas suas declarações formais; se desejarmos saber qual é o seu objetivo real, precisamos observar o que seu pessoal está fazendo.” (ROBBINS, 1981, p.162).

Hasenfeld (1983) afirma que uma das críticas às organizações é quanto ao fato das mesmas apresentarem discrepância entre suas metas declaradas e seu real desempenho. O autor denomina esse fenômeno de discrepância entre metas declaradas e metas operativas. Segundo o autor, as metas declaradas (ou oficiais) servem como mecanismo organizacional, buscando legitimidade e apoio por parte de um amplo grupo social; pois enunciam termos abstratos e vagos, evocando valores e normas amplamente compartilhados. Dessa forma, entende-se que ao analisar os objetivos organizacionais, é preciso estar ciente da existência das metas declaradas (oficiais) e das metas operativas. As metas oficiais, na opinião de Litterer (1977), são de uso público; já as metas operativas consistem na finalidade real da organização. Ambas, segundo o autor, podem diferir em graus de especificidade. 
As metas oficiais são os propósitos gerais da organização que constam nas declarações públicas, informes etc.; já as metas operativas são as metas realmente perseguidas através das políticas operacionais da organização, e demonstram realmente o que a organização está realizando (PERROW,1961). Segundo Perrow (1972), os objetivos oficiais são vagos e geralmente não indicam os reais fatores que influenciam o comportamento organizacional. Os objetivos operacionais, por sua vez, através da tomada de decisão, das práticas pessoais, das alianças organizacionais e das características da elite dominante, conferem ao analista uma percepção das reais atividades da organização e conseqüentemente dos seus reais objetivos, comenta o autor.

Hasenfeld (1983) conclui que as metas oficiais correspondem a um amortecedor entre a organização e o próprio meio, demonstrando se a organização cumpriu ou não com suas promessas públicas, enquanto as metas operativas refletem o emprego real dos recursos organizacionais. As metas oficiais indicam, comumente, valores dominantes e os compromissos normativos da organização, afirma o autor. As negociações e os compromissos entre os membros da coalizão dominante determinarão, segundo o autor, a natureza das metas organizacionais como acordos que emergem sobre a distribuição dos recursos disponíveis.

A partir do comprometimento da organização com um conjunto de metas, a mesma procura responder por elas diante das demais organizações e grupos de interesse que a observam e lhe conferem legitimidade (HASENFELD, 1983).

Marinho (1990) ressalta que pesquisas empíricas ${ }^{2}$ têm demonstrado a dificuldade em identificar os propósitos de uma organização,

não somente porque os objetivos "declarados" quase sempre não correspondem ao que está sendo de fato atingido, mas porque também os objetivos de uma organização não são auto-evidentes como se pensa que eles sejam. (MARINHO, 1990, p.8)

A transformação dos objetivos organizacionais pode emergir em função da coalizão dominante, do advento de novos grupos de interesse, da disponibilidade de recursos ou de mudanças no meio ambiente, ressalta Hasenfeld (1983). O autor elenca dois tipos de metas operativas que estão relacionadas com a transformação das metas organizacionais: as metas reflexivas, que buscam a sobrevivência da organização, e as metas transitivas, que buscam um novo produto em função das pressões do meio ambiente.

Simon (1979) sustenta que a transformação do objetivo organizacional representa, geralmente, a tentativa de conciliar os objetivos de diversos grupos de interesse, almejando, assim, assegurar a cooperação conjunta. Carvalho (1993, p.100) observou em sua pesquisa, que

[...] os grupos de interesse formam-se em torno de objetivos diferentes e por vezes divergentes, não só entre si, mas também em relação aos objetivos da organização, o que se reflete nas situações de conflito entre os atores organizacionais, divididos entre os que desejam manter e aqueles que lutam para mudar a situação existente.

Carvalho (1992) esclarece que a abordagem predominante a respeito dos objetivos organizacionais emergiu de uma perspectiva racionalista. A perspectiva racional buscava a maximização de resultados, exigindo eficiência, confiabilidade, padronização e rotinização no desempenho das atividades organizacionais. Nesse sentido, são ressaltadas as concepções de gerência científica de Taylor (eficiência e alcance da produtividade) e tipo ideal (modelo de organização burocrática) de Weber.

A perspectiva racional, ao visualizar os objetivos organizacionais como algo resultante de uma ação racional e planejada, não contempla, segundo Marinho (1990), o fato de que nenhuma organização pode ser tão estruturada, de forma a conseguir prever toda e qualquer contingência. "Ainda que a organização tente ser racional, ela se compõe de indivíduos com valores e desejos que podem alterar o que acontece na organização, levando a certa incerteza no que diz respeito à prefixação de objetivos." (MARINHO, 1990, p.9). Essa perspectiva tornase inadequada à análise das organizações, ressalta a autora, pois considera apenas os objetivos formais, não incorporando os objetivos dos grupos específicos que também fazem parte da organização. A perspectiva racional concebe os objetivos como estáticos e não sujeitos às incertezas (às mudanças no ambiente organizacional), algo quase inconcebível em estudos envolvendo análise organizacional ou comportamento organizacional. 
$\mathrm{Na}$ tentativa de tornar a análise organizacional mais abrangente, emerge a perspectiva funcionalista, preocupada com a auto-sustentação organizacional. Dessa perspectiva, a organização é concebida como um sistema de partes inter-relacionadas e interdependentes, em que o equilíbrio entre as funções e disfunções de cada uma das partes, torna-se o principal objetivo organizacional, explica Marinho (1990). Ao conceber a organização como um sistema, a perspectiva funcionalista ressalta a preocupação com a busca pelo equilíbrio entre os sistemas como principal objetivo organizacional, bem como apresenta a organização como uma estrutura adaptativa, operando em constante adaptação ao ambiente mutante. As organizações sob uma concepção funcionalista cumprem funções de adaptação, integração, administração de conflitos e tensões, bem como de manutenção (MARINHO, 1990). De uma perspectiva funcionalista, a organização não deixa de estar direcionada por objetivos. Entretanto, cabe ressaltar que as necessidades organizacionais (adaptação, sobrevivência etc.) constituem forças tão importantes quanto os próprios objetivos formais, enfatiza Marinho (1990).

Os objetivos organizacionais, na perspectiva funcionalista, consistem, portanto, no resultado das diversas interações existentes entre a organização e o seu ambiente; “[...] um produto muito mais de pontos de vista conflitivos e contraditórios do que dos consensuais e não contraditórios, como implica a visão radical dos modelos clássicos de organização" conforme expõe Marinho (1990, p.12).

Do ponto de vista da análise dos objetivos, a autonomia existente entre as partes do sistema "organizacional" gera, de certa forma, conflitos de interesses e oposições entre as mesmas. Nesse sentido, Marinho (1990, p.12) conclui que

[...] a definição de organização como sistema permite que a mesma seja concebida como não tendo apenas um, mas múltiplos objetivos, por outro lado, impede de observar o fato de que a estrutura de uma organização composta de suas várias partes não é algo homogêneo, e, sim, moldada por relações de desigualdade.

A posição funcionalista, na opinião da autora e de outros críticos, consistiria portanto, numa reafirmação da crença no paradigma racional.

Na concepção de Marinho (1990) a tentativa de evitar as complicações inerentes aos modelos convencionais, os quais pressupõem a questão dos objetivos como algo facilmente identificável quando se analisa o que é explicitamente declarado pela organização, faz emergir a perspectiva tecnológica. Tal perspectiva sustenta-se a partir das definições de Perrow (1961) sobre objetivos "operacionais" e objetivos "oficiais". A preocupação dessa perspectiva está, portanto, na frágil relação entre os objetivos organizacionais e as atividades de seus integrantes.Os objetivos operacionais, nesse sentido, correspondem aos fins de grupos específicos dentro de uma organização, independente da posição hierárquica, comenta Marinho (1990). Todavia, ressalta a autora, os mesmos não são facilmente identificáveis, são possivelmente visualizados através das principais tarefas da organização ou pelas características da coalizão dominante, conforme afirma Perrow (1978).

No que concerne às tarefas organizacionais a serem analisadas, Perrow (1978) ressalta quatro: o capital necessário ao estabelecimento e expansão da organização, a busca da legitimidade, o domínio de habilidades e a coordenação das atividades dos seus membros, bem como da relação com outras organizações e com os grupos de interesse.

A perspectiva tecnológica procura, portanto, relacionar a natureza do trabalho e da tecnologia com a estrutura de autoridade e os objetivos da organização, conforme expõe Marinho (1990). Tal perspectiva considera os objetivos organizacionais variáveis, reconhece a relação entre a organização e o ambiente como fator de influência na determinação dos objetivos, enfatiza a importância da tecnologia e natureza do trabalho na estruturação interna de poder, demonstrando como de fato os grupos que satisfazem os requisitos das tarefas podem formular os objetivos organizacionais.

Marinho (1990, p.14) sustenta que "[...] os objetivos de uma organização são o resultado da atuação daqueles grupos que assumem, dentro dela, a responsabilidade de solucionar as suas mais cruciais tarefas". Dessa forma, a autora conclui a partir da perspectiva tecnológica que os objetivos podem sofrer mudanças a longo prazo, em 
função da natureza da tarefa a ser desempenhada ou em decorrência da emergência de grupos dominantes na estrutura de poder organizacional.

Outra perspectiva emerge na tentativa de complementar ou refutar as demais. A perspectiva dos objetivos na teoria do processo decisório concebe os objetivos organizacionais como o principal critério para determinar o que será realizado. Tal perspectiva leva em consideração que o objetivo organizacional é resultado da interação entre os membros da organização, comenta Marinho (1990). Os objetivos segundo essa perspectiva, são resultado de negociações entre as diversas coalizões que envolvem a organização, afirma a autora. A organização, segundo essa perspectiva, persegue objetivos múltiplos, conflitantes e quase nunca completamente resolvidos, conclui Marinho (1990).

Ciente de que os objetivos organizacionais não podem ser analisados apenas mediante fatores internos à organização, como propõe a perspectiva anterior, a abordagem da economia política consiste num avanço em relação às perspectivas anteriormente abordadas (MARINHO,1990). A perspectiva da economia política concebe a organização como um sistema aberto, interagindo com a sociedade. No que se refere aos objetivos organizacionais, tal perspectiva acredita que a principal preocupação deve ser a determinação das relações almejadas (concorrência, barganha, cooptação e coalizão) entre a organização e a sociedade. Marinho (1990, p.16) ressalta que "[...] serão bem-sucedidas aquelas organizações que adotem objetivos que a sociedade deseja aceitar. Tenderão, assim, a serem eliminadas aquelas cujos objetivos não correspondem aos objetivos que a sociedade legitima".

Da perspectiva de economia política, as organizações são concebidas conforme suas relações com o contexto, ressaltando o impacto do ambiente nas organizações, negligenciando, porém, o papel das organizações como atores e agentes que podem também influenciar de certa forma o ambiente. Tal perspectiva acredita que as organizações não podem ser analisadas isoladamente, dissociadas do seu ambiente histórico, econômico e político, ressalta Marinho (1990).

A partir da concepção do sociólogo francês Lucien Karpik em relação à questão dos objetivos organizacionais, a perspectiva de economia política adquire maior consistência, pois o mesmo procura distinguir objetivos de estratégia, lógica de ação e políticas. Os objetivos, nesse sentido, consistem nas intenções e situações futuras, almejadas pelos atores, individualmente ou por parte das coalizões. As estratégias, por sua vez, referem-se aos métodos utilizados pelas coalizões ou atores organizacionais na obtenção dos fins desejados. O conceito de lógica de ação refere-se à racionalidade dos atores individuais ou das coalizões organizacionais. Por fim, as políticas consistem nos resultados da ação coletiva, representando a implementação das atividades da coalizão em direção aos objetivos.

Marinho (1990) acredita que a utilização do conceito de lógica de ação permite que o pesquisador diferencie objetivos intencionais (atores organizacionais) dos fins privados (impostos à organização pelos atores dominantes).

Tais distinções capacitam o pesquisador a identificar a coalizão dominante em uma organização e os seus fins privados, bem como permitem compreender que os "objetivos" da organização são, de fato, os fins privados da coalizão que controla os recursos da organização.(MARINHO, 1990, p.19)

Dessa forma, embora a perspectiva de economia política considere o ambiente e as atividades dos atores no processo de formação dos objetivos e ultrapasse as demais abordagens aqui apresentadas, incorporando na análise dos objetivos, aspectos políticos, históricos e econômicos, a mesma ainda requer uma combinação de vários procedimentos metodológicos e interdisciplinares, para de fato ser utilizada na análise de organizações.

Marinho (1990) ressalta que são os indivíduos que possuem objetivos e não as organizações. Na concepção da autora é preciso compreender que os objetivos são dinâmicos, transformam-se constantemente devido ao processo de interação dos indivíduos, bem como pela relação existente entre a organização e seu ambiente.

Perrow (1972) afirma que o conceito de objetivos é um dos mais ambíguos da literatura e que os objetivos na concepção do autor decorrem de vários fatores como: personalidade dos executivos da coalizão dominante, história da organização, ambiente no qual a organização está inserida, normas e valores estabelecidos, tecnologia e 
estrutura organizacional. Na opinião do autor, o estudo dos objetivos organizacionais propicia uma abordagem conceitual das organizações e reflete a singularidade das mesmas, bem como as influências específicas nas categorias tecnológicas e estruturais mais gerais. Segundo o autor, objetivos vulneráveis expõem a organização à dominação por forças oportunistas do ambiente, pois seus instrumentos de trabalho tornam-se incapazes de sustentar a consecução dos objetivos em questão.

Na concepção de Etzioni (1976) existem três fatores que podem influenciar na determinação dos objetivos organizacionais: a personalidade do líder, as forças do ambiente organizacional e a estrutura organizacional. Marinho (1990), por sua vez, afirma que os objetivos organizacionais devem ser analisados como resultados de uma construção social.

Dessa forma, ressalta-se os argumentos de Gameiro, Menezes e Carvalho (2003) quando afirmam que mudanças internas e externas às organizações fazem emergir novos padrões de produção e consumo que, por sua vez, convergem na transformação dos objetivos das organizações. "Novos padrões de consumo, nomeadamente de produtos culturais, conduzem as organizações à flexibilização de seus objetivos e práticas para que, ao atender às novas necessidades, possam ter uma incorporação plena na sociedade moderna." (GAMEIRO; MENEZES; CARVALHO, 2003, p.199). Nesse sentido, a análise dos objetivos de organizações culturais sem fins lucrativos, conforme estudo em questão, torna-se relevante e oportuna. Com base nessas referências, apresenta-se nossa reflexão acerca das transformações observadas nos objetivos dos grupos teatrais estudados.

\section{Desvendando os objetivos de organizações culturais}

A partir da literatura pesquisada sobre objetivos organizacionais, compreendeu-se a importância de se considerar a existência das metas oficiais e das metas operativas, conforme denominadas por Perrow (1972) e Hasenfeld (1983). Na concepção dos autores, as organizações geralmente apresentam discrepância entre suas metas declaradas e sua atuação, que é como Hasenfeld (1983) denomina o desvio das metas operativas em relação às metas declaradas.

No caso do Erro Grupo, organização constituída legalmente em 2001 e formada por quatro membros, constatou-se que os seus objetivos iniciais estavam voltados para o desenvolvimento de intervenções teatrais no cotidiano das pessoas e a experimentação de várias linguagens artísticas. Com o tempo aparece uma preocupação maior com o crescimento e o desenvolvimento de seus integrantes em relação ao trabalho artístico. Atualmente, percebe-se que o grupo está mais preocupado com a captação de recursos financeiros que viabilizem seus trabalhos e, conseqüentemente, possibilitem que atinja seus objetivos.

O fato dos integrantes estarem mais voltados para a captação de recursos, utilizando-se dos benefícios provenientes das leis de incentivo à cultura ou patrocínios, por exemplo, pode ser caracterizado como um desvio da orientação inicial do grupo, apesar do grupo ter uma postura contrária ao sistema utilizado pelo governo para a distribuição dos recursos públicos. Sendo contra ou não, o fato é que o grupo transforma sua orientação em função da sua sobrevivência.

Assim, pode-se afirmar que o Erro Grupo transformou, de certa forma, suas metas operativas, segundo conceito definido por Hasenfeld (1983), em função da carência de recursos. O autor distingue dois tipos de metas ou objetivos, como se prefere denominar neste estudo, as metas reflexivas, relacionadas à sobrevivência da organização, e as metas transitivas, que buscam um novo produto devido às pressões do ambiente. No caso do Erro Grupo, pode-se dizer que as metas reflexivas tornam-se cada vez mais importantes, tendo em vista que as transformações nos objetivos operacionais ocorrem devido à escassez de recursos para manutenção e sobrevivência do grupo.

Observa-se também transformações nos objetivos relacionadas à adoção de novas práticas organizacionais, características de organizações empresariais, cuja racionalidade instrumental é geralmente predominante. Ultimamente, o grupo tem concedido comissão aos integrantes, conforme a quantidade de projetos vendidos a patrocinadores, e praticado também uma remuneração com base no horário despendido às atividades do grupo. 
Entende-se, assim, que outro tipo de diferenciação entre as funções e de relação entre os integrantes passa a ser estabelecido.

Conforme já mencionado, a transformação dos objetivos organizacionais pode decorrer de diversos fatores conforme elencam Perrow (1972) e Hasenfeld (1983). No caso do Erro Grupo acredita-se que as transformações percebidas nos seus objetivos, ou o princípio de alguma alteração nos seus propósitos, emergiram em função da carência de recursos financeiros para o desenvolvimento da organização. Os entrevistados relatam o seu distanciamento em relação às atividades artísticas do grupo, devido ao fato de estarem mais voltados ao entendimento das leis de incentivo à cultura e à aprendizagem no uso de ferramentas de "marketing". Nesse aspecto, ressalta-se a interferência de novos atores na constituição dos objetivos da organização. De acordo com a perspectiva da economia política, os objetivos das organizações são influenciados pelas relações (de concorrência, barganha, cooptação ou coalizão) que são estabelecidas em seu contexto. Novas relações são estabelecidas pelo grupo com o intuito de obter recursos financeiros, e, conseqüentemente, novas interferências são sentidas em seus objetivos.

O grupo teatral Dromedário Loquaz, criado em 1981 e constituído por 15 pessoas, apresenta como objetivo oficial desde a sua formação, contribuir para o bem comum através da realização de obras de cunho cultural, artístico, social, de comunicação e pesquisa, tendo como fim primordial o estudo e o desenvolvimento das matérias referentes ao teatro, mediante oficinas e apresentações3 que correspondem em grande parte à atuação do grupo.

Perrow (1972) ressalta que os objetivos oficiais muitas vezes são vagos e podem não corresponder aos reais fatores que influenciam a organização. Pode-se dizer que o objetivo declarado do grupo Dromedário Loquaz tem uma amplitude maior do que os seus objetivos operacionais, ou seja, o grupo nem sempre consegue atingir todos os propósitos a que se propõe de imediato, porém sua trajetória demonstra que há uma busca constante pela sua consecução.

Em alguns momentos a concretização dos objetivos é prejudicada pela falta de tempo disponível por parte de seus integrantes para com as atividades do grupo, devido às outras ocupações assumidas pelos seus membros, pois a atividade teatral é secundária e os indivíduos têm outras profissões e ocupações além das atividades do Dromedário Loquaz. Conforme relata um dos entrevistados: [...] as pessoas todas têm suas profissões, têm seus compromissos. A gente têm no grupo, assim, desde estudantes a arquitetos, funcionários públicos, professores etc. (Entrevistado 1).

O grupo sempre foi conduzido por algumas pessoas que de certa forma acabam orientando as ações das demais. Os entrevistados denominam de "tripé" as três pessoas que constituem o que se poderia considerar o "grupo dominante" da organização. Entretanto, não se percebe na trajetória recente do grupo a prevalência dessa coalizão. Isso ficou fortemente presente no período em que Isnard Azevedo, um dos idealizadores do grupo, esteve liderando o grupo. Atualmente, percebe-se que o grupo trabalha de forma mais coletiva, que os responsáveis pelo grupo (tripé) atuam juntamente com os núcleos de trabalho estabelecidos. [...] hoje o grupo está fundado nesse tripé, que seria eu, o Silvio e o Pio, onde a gente procura sempre tá trazendo à tona assim os propósitos do grupo e tal. (Entrevistado 1). Segundo o entrevistado, atualmente, há uma preocupação por parte dos integrantes do grupo em manter os propósitos iniciais, embora tenham que adaptar o grupo ao novo contexto social e econômico. Mesmo havendo mudanças na postura da coalizão dominante, ela se torna mais aberta à participação dos demais membros do grupo, pois a preocupação de não se desviar dos objetivos originais parece preponderar.

De modo geral, pode-se afirmar que há congruência entre os propósitos previstos pelo grupo e sua atuação, pois a atividade fim, o "desenvolver pesquisa e a produção teatral" prepondera sobre os demais aspectos.

Percebeu-se que o Erro Grupo apresenta um distanciamento de seus objetivos oficiais e que sua conduta não corresponde aos seus propósitos iniciais, que consistiam em realizar intervenções artísticas no cotidiano das pessoas. O grupo começa a se desviar de seus propósitos no momento em que estão mais voltados à captação de recursos e às atividades que a mesma demanda, ao invés de estarem orientados à realização da sua atividade fim, o desenvolvimento de pesquisas e trabalhos teatrais relacionados ao ambiente urbano. Nesse caso, é evi- 
dente a transformação nos objetivos em função da captação de recursos, que começa a influenciar todo o comportamento do grupo. Outro aspecto que evidencia um distanciamento dos valores e propósitos estabelecidos inicialmente pelo grupo é a incorporação por parte dos integrantes de uma racionalidade instrumental, característica de organizações lucrativas, sem que os mesmos tenham consciência das possíveis transformações decorrentes desse feito. Segundo Monte (2003), uma vez que as organizações sem fins lucrativos passam a adotar modelos de gestão característicos de empresas privadas, sua lógica de atuação tende a ser transformada.

Pode-se dizer que o Erro Grupo passou a utilizar práticas similares às empresas privadas, como remuneração por resultados e concessão de prêmios ou comissão aos integrantes que venderem os projetos do grupo ou estabelecerem contatos com patrocinadores. A incorporação de novas funções e a capacitação de seus integrantes em termos de captação de recursos e estratégias de marketing também podem ser consideradas transformações de caráter instrumental, que tendem a convergir ao longo do tempo em mudanças estruturais na organização, além de distanciarem o grupo de seus propósitos e valores estabelecidos.

Acredita-se que a transformação nos objetivos ou o distanciamento daqueles originariamente estabelecidos pelo Erro Grupo é devido à carência de recursos financeiros e à preocupação com a sobrevivência da organização. Carreira (2002, p.63), em sua pesquisa sobre a prática teatral em Santa Catarina, enfatiza que

[...] os grupos que se organizam motivados pelo ato de fazer teatro, e estruturam seus projetos fundamentados no desejo de alcançar um trabalho cênico de qualidade, descobrem que se encaminham para uma aparente encruzilhada: ou se "profissionaliza", ou se destrói.

O autor demonstra em sua pesquisa que a sobrevivência do trabalho teatral não depende da dedicação exclusiva dos grupos ao "fazer teatral", mas de ações que possibilitem aos grupos manter o desejo de fazer teatro.

Vieira e Carvalho (2003) ressaltam que

Organizações antes conduzidas sob o signo do amadorismo e da intuição, por indivíduos que lhes dedicavam suas melhores habilidades, são hoje levadas a exibir, no novo campo simbólico, um crescendo de profissionalização, uma busca incessante de eficiência nos procedimentos e dirigentes de perfil empresarial.

Dessa forma, pode-se refletir que o conceito de profissionalização permeia fortemente as organizações no meio teatral. Embora muitos prezem a profissionalização no sentido da qualidade dos trabalhos e de atividade remunerada tal qual as demais profissões, a conquista dessa realidade, ou às vezes até mesmo a necessidade de sobrevivência, fazem com que os grupos acabem assumindo valores e práticas característicos do âmbito empresarial, no sentido de capacitação gerencial, de especialização de suas funções (incorporação de funções distintas das artísticas), da contratação de indivíduos competentes para a realização da tarefa (captação de recursos), bem como a remuneração diferenciada entre seus integrantes.

Ainda em relação às transformações nos objetivos organizacionais pode-se dizer que o mesmo não ocorre com o Dromedário Loquaz, pois o grupo ao longo de seus 25 anos de atuação apresenta uma congruência entre os seus propósitos e sua conduta. O grupo sempre buscou desenvolver espetáculos que refletissem sobre o homem e a humanidade, utilizando espaços alternativos. Em relação aos propósitos do grupo, muito se manteve desde a sua formação e não são observadas transformações nesse sentido. Há uma congruência entre os objetivos oficiais do grupo e aqueles efetivamente concretizados.

O Dromedário Loquaz enfrentou períodos de estagnação e de reflexão a respeito da continuidade ou não do grupo, em função do falecimento de seu grande idealizador, Isnard Azevedo, em 1989. Observou-se que após o falecimento de Isnard Azevedo, e diante das influências do contexto no qual está inserido, o grupo começou a se preocupar muito mais com a sua viabilidade do que com os objetivos preestabelecidos.

Em relação à filiação à Gesto (Associação de Produtores Teatrais da Grande Florianópolis) pode-se dizer que a interferência da associação na conduta do grupo é, de certa forma, curiosa. A Gesto se caracteriza como um ator importante nesse contexto, na medida em que viabiliza muitas vezes as condições materiais para a consecução dos objetivos do grupo, por meio de facilitações em exibições de espetáculos e participação em festivais, 
ao mesmo tempo em que garante maior legitimidade ao trabalho desenvolvido. Sua interferência não é direta. Entretanto, a associação pode ser caracterizada como um ator importante na viabilização de alguns dos objetivos do grupo.

Diante da análise realizada a respeito dos objetivos dos grupos Erro Grupo e Dromedário Loquaz, considera-se que o tempo de atuação da organização possa ser um facilitador na concretização da gama de objetivos a que se propõe o grupo. No entanto, não se pode afirmar que o tempo de existência da organização seja um determinante na manutenção de objetivos originais. Talvez, o contexto de criação de cada grupo, épocas diferentes, propostas de grupos teatrais com maior ou menor perspectiva profissionalizante, possam contribuir mais fortemente para a compreensão dessas diferenças.

\section{Reflexões finais}

A contribuição deste estudo concentra-se na análise dos objetivos das organizações culturais sem fins lucrativos no âmbito do teatro, de uma perspectiva longitudinal. Nesse sentido, procurou-se identificar as transformações ocorridas ao longo do tempo nos objetivos das organizações analisadas. Assim, vale ressaltar que se teve por fundamento os pressupostos da literatura sobre objetivos organizacionais, principalmente, em relação à distinção entre as metas oficiais e operacionais, e a reflexão a respeito dos agentes influentes nas transformações dos propósitos organizacionais.

Neste artigo, observou-se que o grupo Dromedário Loquaz vivenciou, ao longo de sua história, momentos de escassez de recursos financeiros para o desenvolvimento de suas atividades; realidade que parece explicar a possibilidade não só de extinção de algumas organizações, mas a dificuldade e quase inviabilidade em manter a atividade teatral no país. Entretanto, o grupo apesar de ter passado por períodos de inércia e estagnação, não teve seu trabalho inviabilizado. Argumenta-se que o fato de seus integrantes não terem a atividade teatral como ocupação principal e fonte de renda possa explicar esse acontecimento.

A influência da carência de recursos e do processo de financiamento nas organizações do campo da cultura é evidente no caso do Erro Grupo, por exemplo. O grupo até então formado para desenvolver a pesquisa teatral e obras de intervenção urbana, está hoje voltado muito mais às questões de financiamento e manutenção do grupo do que para o desenvolvimento artístico. É evidente nesse grupo o distanciamento dos propósitos oficiais da organização, em função das pressões externas que parecem determinar suas condições de sobrevivência.

Hasenfeld (1983) sustenta que a transformação nos objetivos organizacionais pode decorrer de diversos fatores como: das decisões da coalizão dominante, do advento de novos grupos de interesse, da disponibilidade de recursos ou até mesmo de mudanças no meio ambiente. Nesse sentido, no caso do Erro Grupo percebe-se claramente a influência do sistema de financiamento, tanto na estrutura como nos objetivos da organização. $\mathrm{O}$ grupo passa a buscar a especialização de suas tarefas na área de gestão e a adotar práticas de remuneração por meio de comissões na venda dos projetos, que parecem refletir uma conduta característica das organizações lucrativas (empresas).

A ausência de políticas públicas culturais no país é considerada pelos entrevistados como uma das causas da grave situação enfrentada por parte das organizações culturais no Brasil atualmente. $\mathrm{O}$ fortalecimento das organizações privadas como outro importante agente no processo de financiamento tem permitido que o estabelecimento dos critérios de avaliação da produção artística seja a eles delegado. Neste caso, a definição daquilo que tem algum valor cultural passa a ser feita por quem detém o recurso financeiro.

A introdução de mecanismos de renúncia fiscal na "linha de montagem" cultural permitiu o envolvimento de uma outra esfera da sociedade, a empresa privada, no centro de decisão do que é oferecido ao público. Para o bem e para o mal. (CORRÊA, 2004, p.13-14)

A busca por parcerias e alianças tende a ser uma das alternativas constatadas pelos grupos teatrais diante das circunstâncias atuais. Segundo Monte (2003), as organizações não-governamentais também estão sujeitas ao ambiente competitivo, em função da captação e otimização de recursos para o desenvolvimento de seus trabalhos, e essas organizações passam a agir estrategicamente, a exemplo das parcerias e alianças estabelecidas. 
Acredita-se que as parcerias estabelecidas podem estar muitas vezes relacionadas à realização de espetáculos e, conseqüentemente, à captação de recursos e formação de público.

Nesse sentido, percebeu-se que o Dromedário Loquaz, grupo filiado à Gesto (Associação de Produtores Teatrais da Grande Florianópolis), obtém um suporte em termos de condições físicas, materiais e de pessoal que lhe possibilita a concretização de alguns de seus objetivos. Observou-se que o grupo, além de possuir um suporte de trabalho que muitos grupos não possuem, parece obter maior visibilidade (legitimidade) e recursos financeiros para a circulação de seus espetáculos em temporadas mais longas.

Outro elemento emergente, característico das organizações empresariais, é a prevalência da racionalidade instrumental na sua dinâmica interna, com o advento da especialização de tarefas e de práticas de gestão voltadas à eficiência. O Erro Grupo destaca-se como o grupo que evidencia em sua atuação mais recente a influência da racionalidade instrumental, mediante a adoção de instrumentos característicos da iniciativa privada. Observouse nesse caso que a captação de recursos financeiros tornou-se mais importante do que a própria atividade teatral.

Dependendo da fonte financiadora, diferentes transformações podem ocorrer, tanto na estrutura como nos próprios objetivos, a exemplo do que ocorre com o Erro Grupo. Transformações estruturais para obtenção dos recursos financeiros podem convergir, conseqüentemente, no desvio dos objetivos do grupo, pois a captação dos recursos torna-se mais importante do que os próprios propósitos de existência. A obtenção de recursos passa a ser um fim em si mesmo, torna-se mais importante que os próprios objetivos da organização, deixa de ser os meios e ferramentas para a operacionalização dos objetivos e se transforma na finalidade precípua da organização. Trata-se da inversão entre meios e fins, considerada uma das disfunções da burocracia. Esse fato torna-se preocupante na medida em que os demais atores do campo, especificamente demais grupos teatrais, adotem o mesmo comportamento. Se o seu papel na sociedade faz algum sentido em termos de produção cultural, parece evidente que uma lacuna no desenvolvimento social passa a ser estabelecida, na medida em que deixam de existir grupos de teatro efetivamente.

Compreende-se que o meio no qual estão inseridas as organizações culturais lhes impõem valores como eficiência, concebendo o teatro como uma mercadoria, assim como as demais esferas submetidas ao sistema econômico vigente. Segundo Jameson (1997, p.5) "não se pode mais falar de algum lugar 'fora do sistema'". O autor sustenta que na cultura pós-moderna, a própria cultura torna-se um produto. "O que ocorreu é que a produção estética hoje está integrada à produção das mercadorias em geral.” (JAMESON, 1997, p.30). Concorda-se com o autor quando afirma que o capitalismo tardio (multinacional/de consumo) constitui atualmente a forma pura de capital, expandindo-se às áreas até então alheias ao mercado, como o âmbito das organizações culturais, no qual estão inseridos os grupos teatrais aqui analisados, influenciando de certa forma a conduta e os propósitos dessas organizações. 


\section{Referências}

CARREIRA, A. L. A. N. Práticas de produção teatral em Santa Catarina: sobrevivência e busca de identidade. Florianópolis, SC: Udesc, 2002.

CARVALHO, C. A. P. Objetivos organizacionais e conflito intraorganizacional: o caso do serviço social do comércio/Alagoas. Dissertação (Mestrado) - Curso de Pós-Graduação em Administração, UFSC, 1992.

Objetivos versus conflito nas organizações: um estudo de caso. In: ENCONTRO DA ASSOCIAÇÃO NACIONAL DOS PROGRAMAS DE PÓS-GRADUAÇÃO EM ADMINISTRAÇÃO, 17., 1993, Salvador. Anais... Florianópolis: Anpad, 1993. CD-ROM.

CORRÊA, M. B. Do marketing ao desenvolvimento cultural. Belo Horizonte: [s.n.], 2004.

ETZIONI, A. Organizações complexas: um estudo das organizações em face dos problemas sociais. São Paulo: Atlas, 1967.

Organizações modernas. São Paulo: Pioneira, 1976.

GAMEIRO, R.; MENEZES, M. F.;CARVALHO, C. A. Maracatu pernambucano: resistência e adaptação na era da cultura mundializada. In: CARVALHO, C. A.; VIEIRA, M. M. F. (Org.). Organizações, cultura e desenvolvimento local: agenda de pesquisa do Observatório da Realidade Organizacional. Recife: Edufepe, 2003.

GONÇALVES, J. C. S.; MAGALHÃES FILHO, P. A. 0.; ALCÂNTARA, B. C. S. Do ócio ao negócio: a expansão lógica de mercado no futebol de Pernambuco. In: COLÓOUIO INTERNACIONAL SOBRE O PODER LOCAL. GESTÃO XXI, GESTÃO SOCIAL E GESTÃO DO DESENVOLVIMENTO, 9. Caderno de Resumos, Salvador, BA, jun. 2003.

GOULART, S.; MENEZES, M. F.;GONÇALVES, J. C. S. Composição e caracteristicas do campo organizacional dos museus e teatros da Região Metropolitana do Recife. In: CARVALHO, C. A.; VIEIRA, M. M. F. (Org.). Organizações, cultura e desenvolvimento local: agenda de pesquisa do Observatório da Realidade Organizacional. Recife: Edufepe, 2003.

HASENFELD, Y. Organizaciones al servicio del hombre. México: Prentice Hall, 1983.

JAMESON, F. Pós-modernismo: a lógica cultural do capitalismo tardio. São Paulo: Ática, 1997.

LEÃO Jr, F. P S. Museus na Região Metropolitana do Recife: das heranças do passado à construção do futuro. In: CARVALHO, C. A.; VIEIRA, M. M. F. (Org.). Organizações, cultura e desenvolvimento local: agenda de pesquisa do Observatório da Realidade Organizacional. Recife: Edufepe, 2003.

LITTERER, J. A. Análise das organizações. São Paulo: Atlas, 1977.

MADEIRO, G.; CARVALHO, C. A. Da origem pagã às micaretas: a mercantilização do Carnaval. In: CARVALHO, C. A.; VIEIRA, M. M. F. (Org.). Organizações, cultura e desenvolvimento local: agenda de pesquisa do Observatório da Realidade Organizacional. Recife: Edufepe, 2003.

MARINHO, M. S. C. A questão dos objetivos nas organizações. Revista de Administração de Empresas, Rio de Janeiro, v.30, n.2, p.5-22, abr./jun. 1990.

MEGGINSON, L. C.; MOSLEY, D. C.; PIETRI Jr, P. H. Administração: conceitos e aplicações. São Paulo: Editora Aabra Ltda, 1986.

MONTE, T. C. Parcerias entre ONGs e empresas: uma relação de poder camuflada. In: CARVALHO, C. A.; VIEIRA, M. M. F. (Org.). Organizações, cultura e desenvolvimento local: agenda de pesquisa do Observatório da Realidade Organizacional. Recife: Edufepe, 2003.

MOTTA, F. C. P. ;VASCONCELLOS, I. F. G. de Teoria geral da administração. São Paulo: Pioneira Thomson Learning, 2002.

PERROW, C. The analysis of goals in complex organizations. American Sociological Review, 26 Dec. 1961. p.854-866.

Análise organizacional: um enfoque sociológico. São Paulo: Atlas, 1972.

The analysis of goals in complex organizations. In: HASENFELD, Y.; ENGLISH, R. A. Human service organizations. Ann Arbor: The University of Michigan Press, 1978.

ROBBINS, S. P. 0 processo administrativo: integrando teoria e prática. São Paulo:Atlas, 1981.

SIMON, H. Comportamento administrativo: estudo dos processos decisórios nas organizações administrativas. Rio de Janeiro: Editora FGV, 1979. 
VIEIRA, M. M. F.; CARVALHO, C. A. Campos organizacionais: de wallpaper à construção histórica do contexto de organizações culturais em Porto Alegre e em Recife. In: ENCONTRO DA ASSOCIAÇÃO NACIONAL DOS PROGRAMAS DE PÓS-GRADUAÇÃO EM ADMINISTRAÇÃO, 27. 2003, Atibaia. Anais... Florianópolis: Anpad, 2003. CD-ROM.

\footnotetext{
${ }^{1}$ Incorporar em suas práticas organizacionais, atitudes de outros grupos (principalmente, do âmbito empresarial), no que concerne à competitividade, formalização e eficiência, entre outros aspectos característicos do âmbito empresarial. Segundo Motta e Vasconcellos (2002), a idéia de isomorfismo está relacionada à estrutura burocrática como modelo que pode facilmente ser transposto para outras sociedades e incorporado por culturas distintas.
}

${ }^{2}$ GOLDNER, Alvin. Patterns of industrial bureaucracy. Glencoe, Illinois, The Free Press, 1964.

${ }^{3}$ Conforme consta no estatuto social do grupo. 